and management; another leaves the reader in no doubt as to how to manage a urethral stricture in a male patient and the latest urethral stenting techniques are included.

Of particular interest are the chapters on male urethritis and dermatological lesions of the penis. The latter chapter is illustrated with black and white photographs that cannot be faulted.

Within this massive textbook there is reference material that is completely up to date for all those interested in urology and genitourinary medicine.

ROBERT H WHITAKER

All titles reviewed here are available from the BMJ Bookshop, PO Box 295, London WC1H 9TE. Prices include postage in the UK and for members of the British Forces Overseas, but overseas customers should add $£^{2}$ per item for postage and packing. Payment can be made by cheque in sterling drawn on a UK bank, or by credit card (MASTERCARD, VISA or AMERICAN EXPRESS) stating card number, expiry date and full name.

\section{Slide set review}

Sexually Transmitted Diseases by AS Latif and $K$ Murtagh (24 slides + text pp26; $£ 6$ ( $£ 5$ for developing countries, p\&p inc.): Teaching-aids at low cost (TALC) PO Box 49, St Albans, Herts AL1 4AX, United Kingdom.

This set of 24 slides and accompanying text gives an overview of those STDs and their complications that are prevalent in underdeveloped countries. Produced in Zimbabwe and distributed in the UK by Teaching-aids at low cost (TALC) a non profit-making organisation, the set is designed for doctors, nurses, midwives, auxiliaries, primary health care workers and medical students working in areas with limited STD services. Some of the slides are better than others but most are good examples and include algorithms for managing urethral and vaginal discharge and genital ulcer disease (GUD). The text gives a clear commentary on the slides and provides numerous points of interest for teachers of students with differing levels of knowledge. A major emphasis is rightly placed on the diagnosis of GUD which has assumed increasing importance as a co-factor in HIV transmission. There are helpful points in differentiating between the various causes of GUD but no mention is made of donovanosis (granuloma inguinale). A section on congenital infections contains interesting and unusual examples of congenital syphilis. A multiplicity of treatment regimes are covered in the text and are of particular relevance for areas where drugs are in short supply.

Finally, a few words about the price. By any standards this set, on a costper-slide basis alone, is a bargain and should readily find a place in departmental slide libraries. The set can be recommended to those in charge of HIV/STD control programmes for distribution in peripheral areas and also to Western-educated medical staff unfamiliar with STD problems faced by underdeveloped countries.

N O'FARRELL
NOTICE

\section{Northern Genitourinary Physicians Colposcopy Group}

The Annual General Meeting, with a lecture by $\operatorname{Dr} P$ Blomfield, "Lower Orders of CIN-to Treat or Leave?" will take place on 23 November 1991, at $11 \mathrm{am}$, at the Excelsior Hotel, Manchester Airport, Manchester. All members and interested parties are invited. 